(6)

\section{OPEN ACCESS}

${ }^{1}$ Centre of Genomics and Policy, McGill University, Montreal, Quebec, Canada

${ }^{2}$ Department of Social and Preventive Medicine, School of Public Health, Université de Montréal, Montreal, Quebec, Canada

${ }^{3}$ Centre of Genomics and Policy, McGill University, Montreal, Quebec, Canada

\section{Correspondence to}

Erika Kleiderman, Centre of Genomics and Policy, McGill University, Montreal, QC H3A OG1, Canada;

erika.kleiderman@mcgill.ca

Received 27 February 2019

Revised 12 June 2019

Accepted 28 June 2019

Published Online First

20 July 2019

\title{
The 'serious' factor in germline modification
}

\author{
Erika Kleiderman, ${ }^{1}$ Vardit Ravitsky, ${ }^{2}$ Bartha Maria Knoppers ${ }^{3}$
}

\section{ABSTRACT}

Current advances in assisted reproductive technologies aim to promote the health and well-being of future children. They offer the possibility to select embryos with the greatest potential of being born healthy (eg, preimplantation genetic testing) and may someday correct faulty genes responsible for heritable diseases in the embryo (eg, human germline genome modification $(\mathrm{HGGM})$ ). Most laws and policy statements surrounding HGGM refer to the notion of 'serious' as a core criterion in determining what genetic diseases should be targeted by these technologies. Yet, this notion remains vague and poorly defined, rendering its application challenging and decision making subjective and arbitrary. By way of background, we begin by briefly presenting two conceptual approaches to 'health' and 'disease': objectivism (ie, based on biological facts) and constructivism (ie, based on human values). The basic challenge under both is sorting out whether and to what extent social and environmental factors have a role in helping to define what qualifies as a 'serious' disease beyond the medical criteria. We then focus on how a human rights framework (eg, right to science and right to the highest attainable health) could integrate the concepts of objectivism and constructivism so as to provide guidance for a more actionable consideration of 'serious'. Ultimately, it could be argued that a human rights framework, by way of its legally binding nature and its globally accepted norms and values, provides a more universal foundation for discussions of the ethical, legal and social implications of emerging or disruptive technologies.

\section{INTRODUCTION}

Current advances in assisted reproductive technologies (ARTs) aim to promote the health and wellbeing of future children. ${ }^{1}$ They offer, for example, the possibility to select embryos with the greatest potential of being born healthy (eg, preimplantation genetic testing $\left.(\mathrm{PGT})^{\mathrm{i}}\right)$ and, perhaps, one day to correct genes responsible for heritable diseases in the embryo (eg, human germline genome modification $\left.(\mathrm{HGGM})^{\mathrm{ii}}\right)$. ARTs raise the question of

${ }^{i}$ Preimplantation genetic testing (PGT): 'A test performed to analyze the DNA from oocytes (polar bodies) or embryos (cleavage stage orblastocyst) for HLA-typing or for determining genetic abnormalities' (see: Zegers-Hochschild, Fernando, et al. 'The international glossary on infertility and fertility care, 2017'. Fertility \& Sterility (2017), 108(3): 393-406; p. 404). Although the more familiar and well-established term is preimplantation genetic diagnosis (PGD), the literature is moving towards the use of PGT, as it provides greater specificity.

${ }^{i i}$ Human germline genome modification (HGGM): A heritable genetic modification that can be passed on to descendants (see: National Academies of Sciences, Engineering, and Medicine (NAS). (2017) what uses are ethically and socially acceptable and which should be prioritised. For PGT, for example, thresholds of acceptability are gravity, treatability, risk of occurrence of a given disease and more..$^{2-4}$ Past experience with the normative analysis and governance of PGT and prenatal testing can serve as a model to guide similar debates surrounding the acceptability of HGGM.

The announcement of the 'CRISPR babies' in China $^{56}$ and the Second International Summit on Human Genome Editing in Hong Kong (November $2018)^{7}$ put HGGM at the forefront of international policy debates. The general agreement remains that HGGM should not be used for reproductive purposes at this time, as many unknowns remain surrounding its safety, efficacy and transgenerational impacts. Yet, there is emerging consensus on the need for a translational pathway forward. Such a pathway requires adherence to and development of scientifically rigorous and ethically acceptable standards for future clinical research using HGGM, ${ }^{7}$ including which diseases it should be used for first.

Numerous policy discussions (both national and international) surrounding HGGM refer to the notion of 'serious' genetic disease as a core parameter in determining what genetic diseases should be targeted by these technologies and where the line should be drawn. ${ }^{8-12}$ For example, in their 2017 Report, the US National Academies of Sciences, Engineering, and Medicine (NASEM) lists a set of thresholds that must be met for the advancement of HGGM into clinical trials. ${ }^{9}$ These include 'preventing a serious disease or condition' and the need for 'reliable oversight mechanisms to prevent extension to uses other than preventing a serious disease or condition' (p. 8) (emphasis added). ${ }^{9}$ More recently, Quebec's Commission on Ethics in Science and Technology stated that HGGM, if proven to be safe and effective, should be limited to 'very serious, high penetrance diseases, where there are no other reproductive or therapeutic options available' (p. 14). ${ }^{12}$ The German Ethics Council's 2019 Report has also mentioned HGGM's application as an 'interventions to avoid serious monogenic hereditary diseases'. ${ }^{11}$

Wertz and Knoppers ${ }^{8}$ raised the importance of this notion back in 2002. They demonstrated through an international survey that there is insufficient consensus, even among experienced genetics professionals regarding the definition of 'serious' genetic disease within a strictly legal and policy context. They also highlighted that socioeconomic factors are influential in determining individual perceptions of what would be classified as 'serious'. 8 The

Human Genome Editing: Science, Ethics, and Governance. Washington, DC: The National Academies Press.) 
literature suggests it would be unrealistic to expect a universal definition of 'serious' and that when employed it must be qualified and consider both patient and medical perspectives. ${ }^{8}$ This renders the application of this term vague and decision making subjective and perhaps arbitrary. Furthermore, public opinion also appears to converge towards acceptance of HGGM for therapeutic purposes (ie, the treatment and prevention of serious, life-threatening and debilitating diseases). ${ }^{13-18}$

This paper explores whether the notion of 'serious' genetic disease should be qualified by a circumscribed set of criteria (ie, objective approach to decision making limiting or characterising access to HGGM). If so, we consider who should be entrusted with qualifying this notion. We begin by presenting a brief overview of two conceptual approaches: objectivism (ie, emphasis on biological facts) and constructivism (ie, emphasis on human values), which are indispensable tools to situate and provide a basis for understanding and discussing the concepts of 'health' and 'disease'. The challenge under both is sorting out whether and to what extent social and environmental factors have a role in helping to define what qualifies as a 'serious' disease beyond the medical criteria. Moreover, the classification of 'serious' should be flexible enough to include shifting socioeconomic conditions (eg, if burdens are lessened through policies or whether cost of treatment should play a role). Our focus is on how a human rights-based framework (eg, right to science and right to health) could integrate the concepts of objectivism and constructivism to provide guidance for a more actionable consideration of 'serious'. Indeed, we would argue that a human rights framework, by way of its legally binding nature (for States having ratified the international treaties) and its globally accepted norms/ values, provides a more universal foundation for discussions of the ethical, legal and social implications of emerging or disruptive technologies. ${ }^{19}$

\section{CONCEPTIONS OF 'HEALTH' AND 'DISEASE'}

The concepts of 'health' and 'disease' are pivotal in the context of healthcare. The way we define and qualify them has individual, societal and policy implications. Laws and policies employ the notion of 'serious' as a qualifier in determining the circumstances under which HGGM may be used and what genetic diseases it would be acceptable to target. Yet, in most countries, the notion of 'serious' has not been explicitly defined, ${ }^{\text {iii }}$ rendering its application rather limited, dependent on the weight it attributes to physiological, sociocultural and environmental factors. ${ }^{20} \mathrm{~A}$ brief overview of two conceptual approaches is provided below to contextualise the concepts of 'health' and 'disease' within the discussion of what is considered 'serious'. While a comprehensive and in-depth exploration of these approaches goes beyond the scope of this paper, the interested reader can refer to a rich literature that offers such analysis. ${ }^{21-30}$

\footnotetext{
iii The US Food and Drug Administration defines 'serious' as 'a disease or condition associated with morbidity that has substantial impact on day-to-day functioning. Short-lived and self-limiting morbidity will usually not be sufficient, but the morbidity need not be irreversible, provided it is persistent or recurrent. Whether a disease or condition is serious is a matter of clinical judgment, based on its impact on such factors as survival, day-to-day functioning, or the likelihood that the disease, if left untreated, will progress from a less severe condition to a more serious one' (Food and Drugs, 21 C.F.R. 312.300). This appears to be the most clearly articulated definition of 'serious' available.
}

\section{The objectivist approach}

According to one objectivist account, concepts of 'health' and 'disease' are grounded in biology and scientific facts, irrespective of social or cultural attitudes. ${ }^{20}$ Under this premise, 'health' is characterised as normal human functioning (ie, species-typical physiological functions), ${ }^{31}{ }^{32}$ while 'disease' is 'the inability to perform all typical physiological functions with at least typical efficiency' (ie, malfunction of the biological processes) (p. 542). ${ }^{33}$ For objectivists, the line between health and disease is relatively uncontroversial as it is based on facts stemming from the biomedical context, thus, objective and generally free of value-judgments. $^{32}$

Applying objectivism to the qualification of 'serious' results in a narrow definition that leaves no room for behavioural, psychological and social contexts. ${ }^{3134}$ For example, the UK's Human Fertilisation and Embryology Authority has established a list of serious genetic conditions for which preimplantation genetic diagnosis has been licenced in the UK..$^{35}$ This approach has been criticised as limiting access to medical technologies. ${ }^{8}$

\section{The constructivist approach}

Constructivists believe that 'health' and 'disease' cannot be defined solely by an objective list of physiological malfunctions, but rather that norms, values and human judgment play an important role in their framing. ${ }^{32}$ The WHO defines 'health' as 'a state of complete physical, mental and social well-being and not merely the absence of disease or infirmity' (p. 1). ${ }^{36}$ Despite its recognition of the importance of humans' ability to adapt and interact with their environments, it has been criticised for being vague and medicalising social problems. ${ }^{31}$

The lines that are drawn between whether a disease is serious or not, an action is ethical or not and whether an intervention is considered treatment or enhancement are all socially constructed boundaries. ${ }^{32}$ These boundaries vary from one society to another and change over time while exerting influence on decisions as to which treatments should be prioritised and made available. ${ }^{31} 32$ Such an approach can be useful in diffusing the strictly biomedical conception of disease by incorporating social, cultural and psychological aspects of human life, favouring the development of a set of criteria to frame and guide the qualification of what is considered a 'serious' genetic disease. ${ }^{34}$ However, constructivist arguments have been criticised for lacking sufficient biological grounding and being too subjective, making a universal definition difficult to achieve. ${ }^{20}$ Thus, we turn to the examination of a human rights framework to shift the focus away from this dualism and towards a more comprehensive and dynamic framing.

\section{A HUMAN RIGHTS-BASED FRAMEWORK}

At the international level, fundamental human rights are framed by the Universal Declaration of Human Rights (UDHR, 1948) ${ }^{37}$ followed by binding international treaties such as the International Covenant on Economic, Social and Cultural Rights (ICESCR, 1966)..$^{38}$ Despite its foundational status for international human rights, the 1948 UDHR itself is not legally binding, but today could be considered to be part of customary law. ${ }^{39}$ The ICESCR, however, as a legally binding instrument in all 169 nations that have signed and ratified the treaty, has an enforceable 'duty to respect, protect and fulfill the rights articulated [therein]' (p. 899). ${ }^{40}$

An international human rights-based framework, we argue, is a useful way of addressing the ethical, legal and social issues arising in the context of novel technologies. It may be preferable 
to national legislation that addresses each scientific advance, which often becomes outdated. Human rights are both individual and collective, and they encompass both positive duties (ie, urging for governmental action) and negative duties (ie, to refrain from interference). ${ }^{40}$ They serve as principled and practical guides to action and promote responsible translational research. ${ }^{40}$ This can be a promising approach to addressing the proposed translational path forward for HGGM, as there is great uncertainty surrounding what might be the best ethical framework to consider HGGM.

The rationale for such a framework hinges on two main concerns: (1) the limitations of ethical frameworks (as a sole mechanism) to govern and guide healthcare professionals and (2) the 'need to integrate stronger human rights language if professional self-regulation is to be more effective' (p. 69) ${ }^{41} \mathrm{~A}$ human rights framework allows for the effective regulation of behaviour and the establishment of common norms as a result of its legally enforceable mechanisms and universal scope (ie, not imposing one cultural standard). ${ }^{40}$ It sets a baseline standard that can be invoked to ensure the respect of human dignity and to promote the harmonisation of governance. ${ }^{40-42}$ This approach is expanding to influence and shape both the right to science and the right to health as a result of increased knowledge and experience, as well as evolving societal perceptions and challenges. ${ }^{40}$

\section{The right to science}

The right to science was initially recognised 70 years ago in the UDHR under article $27^{1}$ : 'everyone has the right freely to participate in the cultural life of the community, to enjoy the arts and to share in scientific advancement and its benefits' (emphasis added). ${ }^{37}$ This right was later enshrined in article $15^{1}$ (b) of the ICESCR, which recognises the right of everyone 'to enjoy the benefits of scientific progress and its applications' (emphasis added). ${ }^{38}$ As a result of its legally binding nature, article 15 further outlines the obligations of State parties to the treaty to ensure the full realisation of this right and to recognise the benefits of international scientific cooperation. ${ }^{42}$

The right to science is generally perceived as a means through which scientific advances having a benefit for human health can be promoted and shared for the benefit of all. Therefore, it aims to make the benefits of scientific progress accessible to all by removing the key barriers to existing scientific innovations and knowledge and by encouraging new discoveries/innovations. ${ }^{43}$ Obligations related to scientific freedom, access to scientific information and the dissemination of science are also integral parts of the right to science. ${ }^{44}$ As a democratic and participatory right, it 'empowers individuals through its prescription to everyone of an equal opportunity to achieve health and wellness through scientific R\&D' (p. 70). ${ }^{43}$ It is of note that the benefits of scientific advancements include both the resulting material products and the scientific process (ie, methods and knowledge garnered)..$^{40} 45$

For the most part, the right to science has remained dormant, and its scope and normative content poorly elaborated within the literature. ${ }^{395}$ It is only in the last decade that we are seeing an awakening of this right within the context of genomics research. ${ }^{46}$ Scientific innovations have been rapidly evolving and 'changing human existence in ways that were inconceivable a few decades ago' (p. 3). ${ }^{45}$ The right to science is closely related to the right to health (also enshrined internationally), which can also serve as a solid basis for governments to balance benefit sharing and competing interests regarding the promotion of scientific advancement. ${ }^{43}$ This would enable governments to exercise their responsibility regarding the monitoring and assessment of the overall impact of innovations on healthcare systems to protect access and reduce inequalities. ${ }^{43}$

Thus, the State parties to the ICESCR 'must aim to facilitate, rather than hinder, basic and pre-clinical research (with rigorous oversight) using [HGGM] so that knowledge and a deeper understanding can be fostered' (p. 20). ${ }^{44}$ Furthermore, protective measures must also be in place to safeguard against the potential negative impacts resulting from HGGM, which include safety risks, unforeseen implications for future generations and issues of distributive justice. ${ }^{4446}$

\section{The right to the highest attainable standard of health}

A complementary relationship exists between the human right to science and the protection/promotion of health, as they work together to increase knowledge that can serve to decrease and prevent human suffering. ${ }^{40}$ The right to health is a central human right and at the heart of any discussion surrounding HGGM. It is codified and enshrined in various national and international legally binding human rights treaties. Most notably, article $12^{1}$ of the ICESCR recognises 'the right of everyone to the enjoyment of the highest attainable standard of physical and mental health' (emphasis added $)^{38}$ and article $24^{1}$ (d) of the 1989 Convention on the Rights of the Child recognises a child's right to 'the enjoyment of the highest attainable standard of health' both before and after birth. ${ }^{47}$

Although a core right, its realisation is often progressive and dependent on the availability of resources. ${ }^{48}$ In order to realise the right, three key objectives have been identified: (1) the promotion of the right as a 'fundamental human right', (2) the clarification of its scope and content and (3) the identification of good practices for its operationalisation (p. 604). ${ }^{48}$ The realisation of certain obligations such as non-discrimination, development of monitoring indicators and benchmarks, as well as the preparation of a national plan to protect this right are seen as immediate priorities. ${ }^{48}$ HGGM, if proven to be safe and effective for reproductive purposes, could be perceived as a form of preventive personalised medicine and a tool to foster the realisation of the right to health. ${ }^{48}$ It is also conceivable that there will be certain instances where safe HGGM may be the best or only option for couples to have a healthy, genetically related child who would not carry the burden of a debilitating or life-threatening genetic disease. ${ }^{49}$

Hence, we need to reinforce the protection of the welfare of children and future generations born from the technology, by ensuring proper ongoing follow-up and oversight, which in turn will require greater resources. ${ }^{90}$ However, there are numerous unknowns regarding the potential implications for the health of future generations. There is little precedent in clinical research ethics when it comes to intergenerational monitoring. ${ }^{51}$ It involves the current participant (ie, prospective child) and their descendants (ie, multiple generations), which is a unique consideration of germline modification. Thus, the notion of 'intergenerational monitoring' will also be debated in light of the right of the child to the highest attainable standard of health. ${ }^{49} 52$ The 'future generations' approach raises its own share of ethical and logistical issues that go beyond the scope of this paper.

The governance of emerging technologies requires monitoring and regulating health risks and uncertainties. ${ }^{3}$ A degree of uncertainty is inherent, and it is a matter of determining when the technology is deemed 'safe enough' to move along the translational pathway. Many of the uncertainties flagged are also true for natural human reproduction. ${ }^{49}$ Within the context of 'serious' genetic disorders, HGGM could enable couples to have a genetically related child free of the genetic disease in question 
in the absence of other options. ${ }^{53}$ As noted above, the obligation of State parties to 'promote the health of children and protect them from harm' (p. 25) highlights the need to consider the promise of HGGM to potentially prevent or treat serious genetic diseases and the suffering they entail. ${ }^{52}$ Therefore, when developing health-related policies, it is important for policy makers to consider both the obligation to fulfil the right to health and the right of the child to the highest attainable health. ${ }^{41}$

\section{DISCUSSION}

The undefined nature of 'serious' renders its application vague and decision making surrounding what diseases should be targeted for treatment or prevention potentially arbitrary. Two approaches to addressing the notion of 'serious' have been proposed: (1) the creation of lists of serious genetic diseases and (2) the development of criteria that guide case-by-case determinations of what is considered to be 'serious'. It is unrealistic to expect policy makers 'to develop a universally respected definition of serious genetic disorders', and any such definition 'must be qualified to include the judgment of the patient and physician, with the patient making the final, and one hopes, informed, decision' (p. 35). ${ }^{8}$ The NASEM Report (2017) recognises the social relativity of qualifying this concept in that 'different societies will interpret these concepts in the context of their diverse historical, cultural, and social characteristics, taking into account input from their publics and their relevant regulatory authorities' (p. 8). ${ }^{9}$

The literature shows that when polled, there is overlap and difficulty in drawing clear lines between what genetics professionals consider to be serious versus non-serious genetic diseases. ${ }^{8}$ This variability can be attributed to several factors, for example, the way genetic diseases are expressed in different individuals; individual, familial and societal perceptions of the disease; professional or legal definitions of the genetic disease that may be too narrow; and lack of definitional flexibility once enshrined in laws and policies. ${ }^{8}$ Today, parallels can be drawn with the ever-changing interpretations of 'pathogenic' variants with the advent of whole genome sequencing. ${ }^{5455}$ Indeed, the American College of Medical Genetics and Genomics has published a revised list of 59 medically actionable genes that they recommend should be reported as incidental or secondary findings in the context of clinical genomic sequencing, testifying to the ongoing nature of this debate. ${ }^{56}$

Furthermore, the literature highlights that lists of serious genetic diseases-and the possibility of limiting access to services based on a definition of 'serious'-would be highly discriminatory, as it 'place[s] value labels on the lives of people with various kinds of genetic disorders and could lead to further stigmatization of people with disabilities' (p. 35). ${ }^{8}$ Concepts such as 'health', 'disease' and 'serious' should not be defined without considering the adaptation of an individual to a given environment. ${ }^{31}$ Moreover, the distinction between the definitions of 'disease' and 'illness' - whereby the latter considers the subjective reality of human experience-may be useful, as the concept of 'illness' aligns with the constructivist approach and broadens the scope to include both physiological and social aspects. ${ }^{34}$

Against the backdrop of powerful voices that perceive 'precaution' and 'responsible implementation' of emerging genomics technologies as necessitating slower progress or moratoria to address panic and resistance to HGGM, ${ }^{5758}$ a human rights framework can offer a more balanced view. By introducing elements of 'opportunity cost' and the freedom to pursue interventions, it can hence foster a more balanced debate that
Box 1 Transposition of preimplantation genetic testing (PGT) parameters as limits to the potential applications of human germline genome modification (HGGM)

Acceptability of HGGM to prevent or treat a genetic disease:Acceptability of HGGM to prevent or treat a genetic disease:

- Seriousness of the condition.

- Morbidity/mortality.

- Quality of life.

- Level of penetrance (certainty vs risk).

- Level of risk.

- Age of onset.

- Availability of treatment.

- Cost of treatment.

- Nature of the condition: physical/mental/cognitive.

Contextual factors to consider:Contextual factors to consider:

- Social and cultural contexts.

- Familial context (eg, ability or willingness to care for the child).

- Availability of other alternatives.

The box is based on the following source: Ravitsky V, Nguyen MT, Birko S, Kleiderman E, Laberge AM, Knoppers BM. Pre-implantation Genetic Diagnosis: The Road Forward in Canada. Journal of Obstetrics and Gynaecology Canada. 2019;41(1):68-71.

accounts for the value of progress and of implementing technologies that have been deemed safe and effective.

Rather than relying solely on a biomedical objectivist approach for understanding the concepts of 'health' and 'disease', socioeconomic and cultural contexts should be considered, as suggested by the constructivist approach, since they provide a more appropriate basis on which the notion of 'serious' can be framed and elaborated. The integration of these two approaches would be more nuanced and culturally sensitive and would also align with the goals of human rights. We have focused on both the promotion of the right to science and the right to the highest attainable health. These rights provide a legally actionable focus and represent common, internationally agreed on values that can in turn help guide the development of national regulatory approaches. ${ }^{19}$ Thus, human rights may provide a more universal and legitimate foundation on which the governance of 'serious', 'health' and 'disease', as well as HGGM can be built. As suggested by Boggio et $a l,{ }^{19}$ this would offer 'an ideal starting point for building international consensus on governing principles that promote responsible scientific and technological advancements'.

Decisions about what constitutes a 'serious' disease should similarly consider the limitations imposed on the ability of individuals to partake in daily activities as a result of the individual biological and contextual factors involved. ${ }^{59}$ As such, proportional policy making based on a clear assessment and delineation of realistic levels of risk or severity of a disease is important. ${ }^{40}$ Criteria currently considered in the determination of possible applications of PGT can be useful and offer a foundation on which further considerations can be extrapolated within the context of HGGM (see box 1).

For example, take the case of phenylketonuria (PKU), a rare, heritable metabolic disorder in which affected individuals cannot metabolise the amino acid phenylalanine. ${ }^{50}$ PKU is currently part of the newborn screening panel in most industrialised countries to ensure early detection and subsequent intervention. ${ }^{60}$ Infants diagnosed with PKU are placed on a special diet (eg, low 
phenylalanine diet) that they must maintain throughout their lives to prevent the development of severe intellectual disability resulting from their condition. ${ }^{50}{ }^{61}$ Such a postnatal (and lifelong) intervention is demanding and burdensome on the individual (ie, restrictive diet, costly, may not be accessible to all). ${ }^{50}$ In such a context, could the application of HGGM be acceptable if safe and effective?

Based on considerations of the right to health and the right to science, one could argue that we have a moral imperative to pursue basic research that may eventually lead to treatment using HGGM. The goal would be to decrease human suffering and/or improve quality of life, as well as to reduce the burden placed on families and the cost to the healthcare system. Indeed, as has been argued in the literature, HGGM will initially be a costly intervention, which may create barriers to access. ${ }^{62}{ }^{63}$ It will thus be essential to ensure equitable access for those who would benefit from it most. Here again, the notion of 'serious' may be useful in determining who has the most urgent claim to HGGM (eg, families suffering from serious genetic diseases) and therefore should be assisted or favoured to enable equitable access.

Determining what is considered a 'serious' condition provides two different types of policy rationales. First, it provides justified limits of acceptability and helps to delineate what uses of this technology should be deemed permissible versus impermissible. ${ }^{50}$ The justified goal being the promotion of health and improvement of quality of life of future generations, where possible. Second, it provides justifications for potential public funding for the use of the technology to facilitate access to those most in need based on the goal of trying to prevent the most serious conditions. Clarifying the notion of 'serious' can thus foster an equitable and inclusive approach to HGGM while ruling out its most contentious applications. ${ }^{64}$

Finally, when considering a rights-based framework, we must look beyond individual State parties and recognise the joint interests of the State, the users and the public at large to ensure the realisation of the right to science and the right to health (ie, to engage with the public on matters of scientific freedom and innovation, as well as health and the prioritisation of public health issues). ${ }^{41} \mathrm{~A}$ key aspect of the right to science relates to 'the opportunities given to individuals and peoples to make informed decisions after considering both the possible improvements offered by scientific advances and their potential side effects or dangerous usages' (p. 899). ${ }^{40}$ This aligns with the global call for public engagement and deliberation to bring to light societal values and attitudes concerning HGGM and to delineate what society considers to be a scientific "benefit'. ${ }^{45}{ }^{65}$ In turn, results from such deliberations can be integrated into assessments of the risks and benefits to inform future policy making. ${ }^{66}$

\section{CONCLUSION}

The notion of 'serious' genetic disease has been broadly used within the legal and policy spheres, notably in the context of HGGM; yet, it remains undefined. There is a clear need to continue to discuss what we mean by 'serious' today across different countries, on the basis of universal human rights, so that policy applications are clearer and more practicable. Biological and contextual factors should be given consideration to fully comprehend the notion of 'serious'. An integrated approach could thus operationalise the human rights to science and to health by helping determine their scope and content.

The evolving qualification of 'serious' will depend on elements that are constant and objective (eg, morbidity/mortality), ${ }^{4}$ as well as elements that are flexible and evolving (eg, disability as impacted by social arrangements or treatability as impacted by effectiveness and cost of treatment). Furthermore, the responsibility of qualifying this notion does not fall on the shoulders of any one given group but rather merits input from various stakeholders, including physicians, genetic counsellors, patients and their families. ${ }^{848}$ This acknowledges the complexity associated with genetic disease and will help account for the burden experienced from multiple angles (medical, emotional, economic and so on).

Framing scientific progress within a novel human rights-based approach would 'reorient our conversation from policing science to governing society and would shift our focus from avoiding risks to protecting opportunities' (p. 21). ${ }^{66}$ Indeed, this would foster advancements in our ability to treat and prevent disease, while remaining mindful of the need to establish anticipatory governance that provides the necessary flexibility to frame the preventive or therapeutic applications but also adapt to potentially legitimate 'off-label' ones. ${ }^{67}$ Finally, addressing the notion of 'serious' could also profit from future discussion of another human right, that of 'future generations', ${ }^{\text {iv }}$ as the need for intergenerational monitoring will undoubtedly lead to safety, privacy, and consent issues for children not yet born. ${ }^{51}$

Acknowledgements The authors would like to acknowledge the financial contribution of the Canada Research Chair in Law and Medicine.

Contributors All authors were involved in the conception and design of this manuscript. EK carried out the research needed and drafted the first version of the manuscript. VR and BMK provided critical revision and edits to several versions of the manuscript. All authors read and approved the final version of the manuscript. The corresponding author attests that all listed authors meet authorship criteria and that no others meeting the criteria have been omitted.

Funding The authors have not declared a specific grant for this research from any funding agency in the public, commercial or not-for-profit sectors.

Competing interests None declared.

Patient consent for publication Not required.

Provenance and peer review Not commissioned; externally peer reviewed.

Open access This is an open access article distributed in accordance with the Creative Commons Attribution Non Commercial (CC BY-NC 4.0) license, which permits others to distribute, remix, adapt, build upon this work non-commercially, and license their derivative works on different terms, provided the original work is properly cited, appropriate credit is given, any changes made indicated, and the use is non-commercial. See: http://creativecommons.org/licenses/by-nc/4.0/.

\section{REFERENCES}

1 Assisted Human Reproduction Act, SC 2004, c.2, s.2.

2 Knoppers BM, Isasi RM. Regulatory approaches to reproductive genetic testing. Hum Reprod 2004;19:2695-701.

3 Isasi R, Kleiderman E, Knoppers BM. Editing policy to fit the genome? Science 2016;351:337-9.

4 Ravitsky V, Nguyen MT, Birko S, et al. Pre-implantation Genetic Diagnosis: The Road Forward in Canada. J Obstet Gynaecol Can 2019:41:68-71.

5 Kolata G, Wee S-L, Belluck P. Chinese scientist claims to use CRISPR to make first genetically edited babies: The New York Times, 2018:26.

6 Belluck P. How to stop rogue gene-editing of human embryos?: The New York Times 2019. https:/www.nytimes.com/2019/01/23/health/gene-editing-babies-crispr.html

7 Baltimore D, Charo A, Daley GQ, et al. Statement by the Organizing Committee of the Second International Summit on Human Genome Editing. 2018. http://www8 nationalacademies.org/onpinews/newsitem.aspx?RecordID=11282018b

8 Wertz DC, Knoppers BM. Serious genetic disorders: can or should they be defined? Am J Med Genet 2002;108:29-35.

9 National Academies of Sciences, Engineering, and Medicine. Human genome editing: science, ethics, and governance. Washington DC: The National Academies Press, 2017:328.

\footnotetext{
${ }^{\text {iv }}$ The UNESCO Declaration on the Responsibilities of the Present Generation Towards Future Generations (1997) purports that ' $[\mathrm{t}]$ he present generations have the responsibility of ensuring that the needs and interests of present and future generations are fully safeguarded' (art. 1) (emphasis added).
} 
10 Brokowski C. Do CRISPR germline ethics statements cut it? Crispr J 2018:1:115-25.

11 Ethikrat D. Intervening in the human germline: Opinion (Executive summary \& recommendations). 2019. https://www.ethikrat.org/en/press-releases/2019/ethicscouncil-germline-interventions-currently-too-risky-but-not-ethically-out-of-thequestion/

12 Commission de l'éthique en science et en technologie (CEST). Genetically modified babies: Ethical issues raised by the genetic modification of germ cells and embryos (Summary and recommendations), 2019.

13 McCaughey T, Sanfilippo PG, Gooden GE, et al. A global social media survey of attitudes to human genome editing. Cell Stem Cell 2016;18:569-72.

14 Blendon RJ, Gorski MT, Benson JM. The public and the gene-editing revolution. N Eng J Med 2016:374:1406-11.

15 Uchiyama M, Nagai A, Muto K. Survey on the perception of germline genome editing among the general public in Japan. J Hum Genet 2018:63:745.

16 Funk C, Hefferon M. Public views of gene editing for babies depend on how it would be used. Washington, DC: Pew Research Center, 2018.

17 Riggan KA, Sharp RR, Allyse M. Where will we draw the line? public opinions of human gene editing. Qual Health Res 2019.

18 McCaughey T, Budden DM, Sanfilippo PG, et al. A need for better understanding is the major determinant for public perceptions of human gene editing. Hum Gene Ther 2019;30:36-43.

19 Boggio A, Knoppers BM, Almqvist J, et al. The human right to science and the regulation of human germline engineering. Crispr J 2019;2:134-42.

20 Sade RM. A theory of health and disease: the objectivist-subjectivist dichotomy. J Med Philos 1995:20:513-25.

21 Nordenfelt L. Towards a theory of happiness: a subjectivist notion of quality of life. Concepts and measurement of quality of life in health care: Springer, 1994:35-57.

22 Hausman DM. Is an overdose of paracetamol bad for one's health? The British Journal for the Philosophy of Science 2011;62:657-68.

23 Nordenfelt L. Standard circumstances and vital goals: comments on Venkatapuram's critique. Bioethics 2013;27:280-4.

24 Venkatapuram S. Health justice: an argument from the capabilities approach: John Wiley \& Sons, 2013.

25 Venkatapuram S. Health, vital goals, and central human capabilities. Bioethics 2013:27:271-9.

26 Boorse C. A second rebuttal on health.J Med Philos 2014:39:683-724.

27 Kingma E. Situation-specific disease and dispositional function: table 1. The British Journal for the Philosophy of Science 2016:67:391-404.

28 Tengland PA. Venkatapuram's capability theory of health: a critical discussion. Bioethics 2016;30:8-18.

29 Nordenfelt L. A defence of a holistic concept of health. Naturalism in the philosophy of health: Springer, 2016:209-25.

30 Nordenfelt L. Functions and health: towards a praxis-oriented concept of health. Biological Theory 2018:13:10-16.

31 Kovács J. The concept of health and disease. Med Health Care Philos 1998;1:31-9.

32 Daniels N. Normal functioning and the treatment-enhancement distinction. Camb Q Healthc Ethics 2000:9:309-22.

33 Boorse C. Health as a theoretical concept. Philos Sci 1977;44:542-73.

34 Farre A, Rapley T. The new old (and old new) medical model: four decades navigating the biomedical and psychosocial understandings of health and illness. Healthcare 2017; $5: 88$.

35 Human Fertilisation \& Embryology Authority (HFEA). PGD conditions. https://www. hfea.gov.uk/pgd-conditions/

36 World Health Organization (WHO). Constitution of the World Health Organization. 2006 https://www.who.int/governance/eb/who_constitution_en.pdf

37 United Nations, General Assembly. Universal Declaration of Human Rights. 1948 https://www.un.org/en/universal-declaration-human-rights/

38 United Nations Human Rights Office of the High Commissioner. International Covenant on Economic, Social and Cultural Rights. 1966 https://www.ohchr.org/en/ professionalinterest/pages/cescr.aspx

39 Shaver $L$. The right to science and culture. Wis $L$ Rev 2010:121-84.
40 Knoppers BM, Harris JR, Budin-Ljøsne I, et al. A human rights approach to an international code of conduct for genomic and clinical data sharing. Hum Genet 2014;133:895-903.

41 London L. What is a human-rights based approach to health and does it matter? Health Hum Rights 2008;10:65-80.

42 Chapman A, Wyndham J. A human right to science. Science 2013;340:1291.

43 Boggio A, W. L. Ho C. The human right to science and foundational technologies. The American Journal of Bioethics 2018;18:69-71.

44 Kleiderman $E$. The regulation of human germline genome modification in Canada. In: Boggio A, Almqvist J, Romano CPR, eds. Human germline genome modification and the right to science: a comparative study of national laws and policies. Cambridge: Cambridge University Press, 2019 [forthcoming].

45 UN General Assembly. Report of the special rapporteur in the field of cultural rights, Farida Shaheed, 2012

46 Yotova R, Knoppers BM. The right to benefit from science and big data. European Journal of International Law. In Press. 2019.

47 United Nations Human Rights Office of the High Commissioner. Convention on the rights of the child. $1989 \mathrm{https}$ ://www.ohchr.org/en/professionalinterest/pages/crc.aspx

48 Hunt $P$. The human right to the highest attainable standard of health: new opportunities and challenges. Trans R Soc Trop Med Hyg 2006;100:603-7.

49 Harris J. Germline modification and the burden of human existence. Camb Q Healthc Ethics 2016;25:6-18.

50 Gyngell C, Bowman-Smart H, Savulescu J. Moral reasons to edit the human genome: picking up from the Nuffield report. J Med Ethics 2019;45:513-22.

51 Cwik B. Designing Ethical Trials of Germline Gene Editing. N Engl J Med 2017:377:1911-3.

52 Zillén K, Garland J, Slokenberga S. The rights of children in biomedicine: Challenges posed by scientific advances and uncertainties, 2017.

53 Cavaliere G. Genome editing and assisted reproduction: curing embryos, society or prospective parents? Med Health Care Philos 2018;21:215-25

54 Gutierrez-Rodrigues F, Calado RT. The interpretation of rare or novel variants: Damaging vs. disease-causing. Hematology, Transfusion and Cell Therapy 2018;40:3-4.

55 Scherer A. Clinical variant analysis: Applying ACMG guidelines to analyze germline diseases, 2019

56 Kalia SS, Adelman K, Bale SJ, et al. Recommendations for reporting of secondary findings in clinical exome and genome sequencing, 2016 update (ACMG SF v2.0): a policy statement of the American College of Medical Genetics and Genomics. Genet Med 2017;19:249-55.

57 Lander ES, Baylis F, Zhang F, et al. Adopt a moratorium on heritable genome editing Nature 2019;567:165-8.

58 Adelman B, Albright C, Andrews L, et al. Letter to the Secretary of the U.S. Department of Health and Human Services. 2019 https://www.asgct.org/global/documents/ clinical-germline-gene-editing-letter.pdf.

59 Reproductive Technology Council. Policy on approval of diagnostic procedures involving embryos, 2008.

60 Therrell BL, Padilla CD, Loeber JG, et al. Current status of newborn screening worldwide: 2015. Semin Perinatol 2015:39:171-87.

61 Davison J. Gene editing: a view through the prism of inherited metabolic disorders: Taylor \& Francis, 2018.

62 Salkever A, Wadhwa V. When baby genes are for sale, the rich will pay. 2017. http:/ fortune.com/2017/10/23/designer-babies-inequality-crispr-gene-editing/

63 Heggie J. Should we edit the human germline? 2018. https://www. nationalgeographic.com/science/2018/11/partner-content-genom-editing/

64 Dondorp W, de Wert G. Refining the ethics of preimplantation genetic diagnosis: A plea for contextualized proportionality. Bioethics 2019:33:294-301.

65 Jasanoff S, Hurlbut JB, Saha K. CRISPR democracy: Gene editing and the need for inclusive deliberation. Issues in Science and Technology 2015;32:25-32.

66 Juengst ET. Crowdsourcing the Moral Limits of Human Gene Editing? Hastings Cent Rep 2017;47:15-23.

67 Juengst ET, Henderson GE, Walker RL, et al. Is Enhancement the Price of Prevention in Human Gene Editing? Crispr J 2018;1:351-4. 